\section{AB0588 INFECTION AGGRAVATED DECREASE OF THE LEVEL OF TH17 AND TREG CELLS AND LOW- DOSE IL-2 REBALANCED TH17/TREG IN THE PERIPHERAL BLOOD OF PATIENTS WITH IDIOPATHIC INFLAMMATORY MYOPATHY}

Y. Liang ${ }^{1}$, H. Y. Wen ${ }^{1}$, Y. Duan ${ }^{1}$, Y. Liü ${ }^{2}$, Z. Yu ${ }^{1}$, W. Niu' ${ }^{1}$, C. Gao ${ }^{3} .{ }^{1}$ The Second Hospital of Shanxi Medical University, Rheumatology, Taiyuan, China; ${ }^{2}$ Shanxi Bethune Hospital, Rheumatology, Taiyuan, China; ${ }^{3}$ Brigham and Women's Hospital, Harvard Medical School, Department of Pathology, Boston, United States of America

Background: Idiopathic inflammatory myopathies (IIM) are featured by a series of clinical presentation such as proximal muscle weakness, increased serum levels of creatine kinase and other muscle enzymes and involvement of other organs and systems ${ }^{[1,2]}$, which results in high morbidity and early mortality ${ }^{[3]}$. We have known the changes of the level of Th17 and Treg cells in IIM in previous studies ${ }^{[4-6]}$. However, whether infection affects lymphocyte subsets or not and whether the effect of low-dose interleukin-2 (IL-2) can be influenced by the use of immunosuppressants or not are still unclear.

Objectives: The study aimed to explore the changes of lymphocyte subsets in patients of IIM with or without important organ infection, and the restoration of Th17/Treg after receiving low-dose IL-2.

Methods: A total of $118 \mathrm{IIM}$ patients were enrolled and classified into infection group and non-infection group based on the important organ infection. Of them, 48 cases were treated with low dose IL-2 $\left(5.0^{*} 10^{5}\right.$ IU for 5 days). The absolute number of peripheral total $\mathrm{T}, \mathrm{B}, \mathrm{CD} 4^{+} \mathrm{T}, \mathrm{CD} 8^{+} \mathrm{T}, \mathrm{NK}$, Th1, Th2, Th17 and Treg cell subsets were analyzed by flow cytometry combined with absolute counting beads. Clinical data, laboratory examinations and the levels of peripheral lymphocyte subsets were analyzed retrospectively.

Results: In these patients, especially in the infection group, the absolute number of $\mathrm{T}, \mathrm{CD} 4^{+} \mathrm{T}, \mathrm{CD} 8^{+} \mathrm{T}, \mathrm{NK}, \mathrm{Th1}, \mathrm{Th} 2, \mathrm{Th} 17$ and Treg cells were significantly decreased as compared with that in the healthy controls, which were significantly increased by low dose IL-2 (especially Treg cells) treatment. The levels of ESR, $\mathrm{LDH}$ and HBDH and the ratio of Th17/Treg were significantly lower than those before IL-2 treatment $(Z=-2.237,-2.083,-2.140,-3.663, P=0.025,0.037,0.032$, 0.000 ). The 48 cases who received IL-2 treatment were divided into 2 groups according to whether they used immunosuppressants. There was no significant difference in the absolute number of T, B, CD4 ${ }^{+} \mathrm{T}, \mathrm{CD} 8^{+} \mathrm{T}$, Th1, Th2, Th17 and Treg cells, the proportion of Th17 and Treg cells and the ratio of Th17/Treg between the 2 groups $(P>0.05)$.

Conclusion: Global decrease in lymphocyte subsets was found in IIM patients, especially those who had important organ infection. A significant re-balance of Th17/Treg was observed after receiving treatment with low-dose IL-2. Furthermore, the restoration of lymphocyte subsets showed similar degree after treatment with or without immunosuppressants. Low-dose IL-2 may become a potential therapy for IIM patients. The mechanism of lymphocyte decrease in IIM is required further to study.

References:

[1] Clark K E N, Isenberg D A. A review of inflammatory idiopathic myopathy focusing on polymyositis[J]. European Journal of Neurology, 2017.

[2] Tieu J, Lundberg IE, Limaye V. Idiopathic inflammatory myositis. Best Pract Res Clin Rheumatol. 2016. 30(1): 149-68.

[3] Mandel DE, Malemud CJ, Askari AD. Idiopathic Inflammatory Myopathies: A Review of the Classification and Impact of Pathogenesis. Int J Mol Sci. 2017. 18(5).

[4] Zhang SX, Wang J, Sun HH, et al. Circulating regulatory T cells were absolutely decreased in dermatomyositis/polymyositis patients and restored by low-dose IL-2. Ann Rheum Dis. 2019.

[5] Espinosa-Ortega F, Gómez-Martin D, Santana-De Anda K, Romo-Tena J, Villaseñor-Ovies P, Alcocer-Varela J. Quantitative T cell subsets profile in peripheral blood from patients with idiopathic inflammatory myopathies: tilting the balance towards proinflammatory and pro-apoptotic subsets. Clin Exp Immunol. 2015. 179(3): 520-8.

[6] Feng $\mathrm{M}$, Guo $\mathrm{H}$, Zhang $\mathrm{C}$, et al. Absolute reduction of regulatory $\mathrm{T}$ cells and regulatory effect of short-term and low-dose IL-2 in polymyositis or dermatomyositis. Int Immunopharmacol. 2019. 77: 105912.

Acknowledgments: Thanks for the support of my teachers, classmates and my family.

Disclosure of Interests: None declared

DOI: 10.1136/annrheumdis-2020-eular.5255

\section{AB0589 \\ THE IMPORTANCE OF A SYSTEMIC SCLEROSIS CLINIC IN A TERTIARY REFERRAL CENTER - A PORTUGUESE EXPERIENCE}

P. Martins $^{1,2}$, E. Dourado ${ }^{1,2}$, J. E. Fonseca ${ }^{1,2}$, I. Cordeiro ${ }^{1,2}$, C. Resende ${ }^{1}$ ${ }^{1}$ Serviço de Reumatologia e Doenças Ósseas Metabólicas, Hospital de Santa Maria, Centro Hospitalar Universitário Lisboa Norte, CHULN, Centro Acad émico de Medicina de Lisboa, Portugal, Lisbon, Portugal; ${ }^{2}$ Unidade de Investigação em Reumatologia, Instituto de Medicina Molecular, Faculdade de Medicina, Universidade de Lisboa, Centro Académico de Medicina de Lisboa, Portugal, Lisboa, Portugal

Background: Systemic sclerosis (SSc) is a rare systemic rheumatic disease (SRD) characterized by small vessel inflammation and fibrosis of skin and internal organs. Pulmonary and cardiac involvement contribute to both morbidity and mortality associated with the disease. A multidisciplinary approach with strict monitoring is therefore key to attain clinical success.

Objectives: To describe the organization and patient pathways of our SSc outpatient clinic.

Methods: Observational study using data extracted from Reuma.pt/SSc (a subset of the Rheumatic Diseases Portuguese Register). Data extracted included demographic variables and clinical and immunological manifestations. The disease was classified according to the 2013 ACR/EULAR criteria. Our SSc clinic is managed by two dedicated Rheumatologists and up to two Rheumatology residents on a weekly basis, but it is a dynamic multidisciplinary clinic where various medical specialties collaborate closely. There are two associated subspecialty clinics (pulmonary hypertension and pulmonary fibrosis) where the Rheumatologists engage with pneumologists and cardiologists, allowing greater collaboration in the management of these patients. Patients' data is systematically registered in Reuma.pt/ $\mathrm{SSc}$ as a part of the routine activity of this clinic, contributing to real-world data on SSc.

Results: A total of 220 patients were registered between July 2011 and June 2019. $196(89.1 \%)$ were female, with a mean age of $58.9 \pm 14$ years and a mean disease duration of $14.6 \pm 9$ years. Ninety-seven patients $(44.1 \%)$ had limited cutaneous SSc, $52(23.6 \%)$ had diffuse cutaneous SSc, $35(15.9 \%)$ had overlap SSc, 24 (10.9\%) had preclinical SSc and $12(5.4 \%)$ had SSc sine scleroderma. Raynaud phenomenon was present in $92 \%$ of the SSc patients and $40 \%$ had a history of digital ulcers. Gastrointestinal manifestations included esophageal dismotility in $39.5 \%$ of patients, gastric disease in $24.4 \%$ and intestinal involvement in $15.5 \%$. Pulmonary involvement was found in $47.6 \%$ of SSc patients, heart disease in $43.6 \%$ and kidney involvement in only two patients. Antinuclear antibodies were positive in $92.2 \%$ of the patients, anti-centromere in $44.1 \%$, anti-topoisomerase I antibodies in 39.1\%, anti-U1RNP in $4.5 \%$ and only three patients had anti-PM-Scl and one had anti-RNA polymerase III. 31 patients were lost to follow-up and 32 died. 18 patients are currently being followed up in the pulmonary hypertension clinic and seven in the pulmonary fibrosis clinic.

Conclusion: The implementation of a standardized approach with regular multidisciplinary work has proven very helpful in evaluating patients with SSc. The continuous registry of patients in Reuma.pt/SSc has been essential for patient care, research and healthcare planning.

Disclosure of Interests: None declared

DOI: 10.1136/annrheumdis-2020-eular.2958

\section{AB0590 CLINICAL AND DEMOGRAPHIC CHARACTERISTICS OF PATIENTS WITH ANTISYNTHETASE AUTOANTIBODIES: DATA FROM A PORTUGUESE TERTIARY OUTPATIENT CLINIC}

P. Martins ${ }^{1,2}$, E. Dourado ${ }^{1,2}$, A. T. Melo ${ }^{1,2}$, N. Khmelinskii ${ }^{1,2}$, I. Cordeiro ${ }^{1,2}$, R. Campanilho-Marques ${ }^{1,2} .^{1}$ Serviço de Reumatologia e Doenças Ósseas Metabólicas, Hospital de Santa Maria, Centro Hospitalar Universitário de Lisboa Norte, Centro Académico de Medicina de Lisboa, Lisbon, Portugal; ${ }^{2}$ Unidade de Investigação em Reumatologia, Instituto de Medicina Molecular, Faculdade de Medicina, Universidade de Lisboa, Centro Académico de Medicina de Lisboa, Lisboa, Portugal, Lisbon, Portugal

Background: Antisynthetase syndrome (AS) may have different clinical phenotypes and outcomes associated with different anti-aminoacyl RNA-synthetase (anti-ARS). Patients may also present with incomplete/early phenotypes that do not fulfil the classification criteria.

Objectives: To evaluate the clinical and demographic characteristics of patients positive for anti-ARS in our Myositis clinic. 